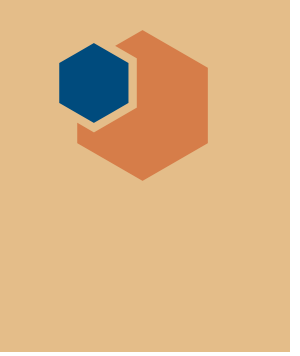

\section{U.S. Congress renews America COMPETES Act}

$\mathrm{T}^{\mathrm{s}}$ he U.S. House of Representatives joined the Senate in late December 2010 in passing the America COMPETES Reauthorization Act of 2010, which aims to boost the country's economic competitiveness by setting funding guidelines that increase federal support for science education and basic research.

"As Norm Augustine, chairman of the National Academies' Gathering Storm panel and former chairman and CEO of Lockheed Martin said, in all the years he was an aircraft engineer and dealing

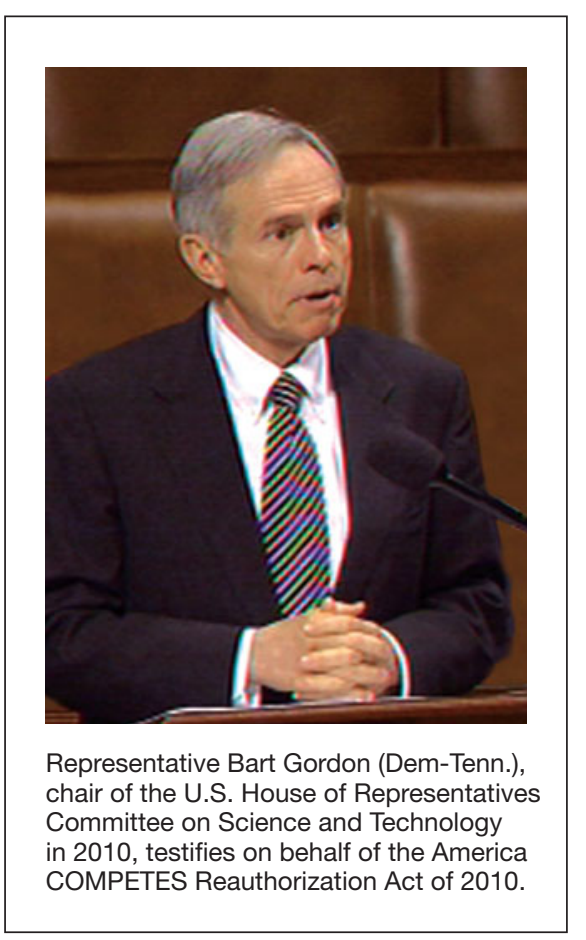

with trying to make an overweight aircraft fly, the solution was never to lop off an engine. Science funding is the engine of a knowledge-based economy. If we remove it, our economy will crash and burn," said Representative Bart Gordon (Dem-Tenn.), then chair of the House Committee on Science and Technology and author of the legislation. "If we are to reverse the trend of the last 20 years, during which our country's technological edge in the world has diminished, we must make the investments necessary today. More than half of our economic growth since World War II can be attributed to development and adoption of new technologies. These investments are the path toward sustainable economic recovery and growth and the path toward prosperity for the next 50 years."

The Senate passed the reauthorization act unanimously on December 17th and the House passed it by a bipartisan vote of 228 to 130 on December 21st.

First passed in 2007, the act is based on the recommendations of the National Academies' report Rising Above the Gathering Storm, which recommended investments to support basic research; improve science, technology, engineering, and math (STEM) education; and foster innovation.

In September, Rising Above the Gathering Storm, Revisited: Rapidly Approaching Category 5 was released. The updated report highlights progress that has been made in the past five years, including enactment of the America COMPETES Act, but underscores that the U.S. competitive position in the world now faces greater challenges and that research investments are even more critical today. The report urges reauthorization of COMPETES.

The reauthorized America COMPETES Act continues to double the authorized funding for the National Science Foundation and the Department of Energy's Office of Science over 10 years, which will end in Fiscal Year 2013.

Under the new COMPETES law, Department of Energy laboratories will be partners in this effort in several ways, including "adopting" schools to strengthen their math and science capability. The new law also extends programs that strengthen the skills of math and science teachers and encourages mathematicians and scientists to become teachers.

Senator Jeff Bingaman (Dem-New Mexico), chair of the Committee on Energy and Natural Resources, said, "When we first passed America COMPETES three years ago, it helped us create a path to ensuring that we can retain our competitive edge in the global economy. Given the difficult economic climate we've been facing for the past few years, I believe it is more important than ever for us to invest in math and science. Extending the America COMPETES Act will help keep us on track - in research and in education - so that we can create the jobs of the future."

Bingaman, Senator Lamar Alexander (Rep.-Tenn.) and then-Senator Pete Domenici (Rep.-New Mexico) were part of a core bipartisan group that began the push for passage of a U.S. competitiveness bill several years ago.

President Obama signed the bill on January 4, 2011.
EU Metrology Program addresses diverse fields www.emrponline.eu

$\mathrm{T}$ hrough the European Metrology Research Program (EMRP), which receives $50 \%$ of its funding through the European Union's (EU) Seventh Frame- work Program (FP7), metrologists are addressing worldwide challenges in diverse fields such as the environment, energy, and health. Metrology refers to the science and application of measurement. 
According to EMRP chair Jörn Stenger of the Physikalisch-Technische Bundesanstalt (PTB) in Germany, "Metrology affects all areas of our lives." For example, metrology ensures that the dose of radiation received during a computer tomography (CT) scan will be enough to generate the scan while remaining within safe limits. Similarly, if different parts of a car are built in different companies and countries, metrology ensures that the parts fit together in the assembly plant.

National metrology institutes exist throughout Europe, and they have a long history of international cooperation, as the mutual acceptance of standards and measures across borders is essential. For many years, this cooperation was fairly informal. However, that all changed when the institutes recognized what Stenger calls a "metrological dilemma."

Advances in technology meant research was becoming increasingly expensive, yet national metrology institutes' budgets were at best stable and at worst declining. Since primary measurement standards must be at the forefront of technology to be able to serve all stakeholder needs, metrology is very research intensive. "We agreed that only a joint approach in metrology research could help us out of this dilemma," Stenger said.

The group obtained funding from the EU for a project called IMERA (implementing metrology in the European research area). This project, financed under the ERA-NET scheme, allowed Europe's metrology community to formulate a joint, coordinated research program and determine the procedures and structures needed to implement it.

When the first IMERA project ended, the metrologists carried on working through the EU ERA-NET Plus scheme. During this period, the group issued calls for proposals in four key areas: health, the international system of units (SI units), electromagnetism, and dimensional industrial applications.

Projects funded in the SI units field address the challenges of measuring constants of nature to redefine SI units such as the kilogram and the Kelvin. The medical projects focus on, among other things, ensuring that diagnostic tests are precise and reliable enough for a doctor to decide confidently whether treatment is needed.

The topic of dimensional matters covers everything from what constitutes a nanoparticle to measuring the larger distances involved, for example, in manufacturing an airplane, where all components must be precisely fabricated. The electricity projects address various issues including the safe dose for electromagnetic radiation.

In 2009, the EMRP secured the future of the joint research program between the participating Member States and the European Union for a further seven years, with the intention that countries integrate their national research programs more deeply into a single European program.

The EMRP is also generating interest beyond Europe's borders; countries that are particularly interested in the EMRP's work include Australia, Japan, Russia, South Korea, Taiwan, and the United States. In addition, a number of researchers from outside Europe are involved in EMRP-funded projects.

Looking to the future, the EMRP is asking stakeholders in a number of sectors, including energy, the environment, and health, for feedback on the metrology problems that are specific to their sector.
Joint R\&D clean energy center established by India and U.S. www.indousstf.org

$\mathrm{A}^{\mathrm{n}}$ $\mathrm{n}$ agreement has been signed between the United States Department of Energy and the Government of India in November 2010 to establish an Indo-U.S. Joint Clean Energy Research and Development Center (JCERDC) to Enhance Cooperation on Energy Secu- rity, Energy Efficiency, Clean Energy, and Climate Change. The goal for the center is to spur collaborative research and development between U.S. and Indian researchers on potentially breakthrough clean energy technologies.

The Indian and U.S. governments have committed $\$ 5$ million per year for five years (subject to yearly appropriations) for the Center and the consortia will match the government funding with its own funds. Under this arrangement, both governments have agreed to invite proposals through a joint India-U.S. Funding Opportunity Announcement in the three priority areas of building efficiency, solar energy, and advanced biofuels.
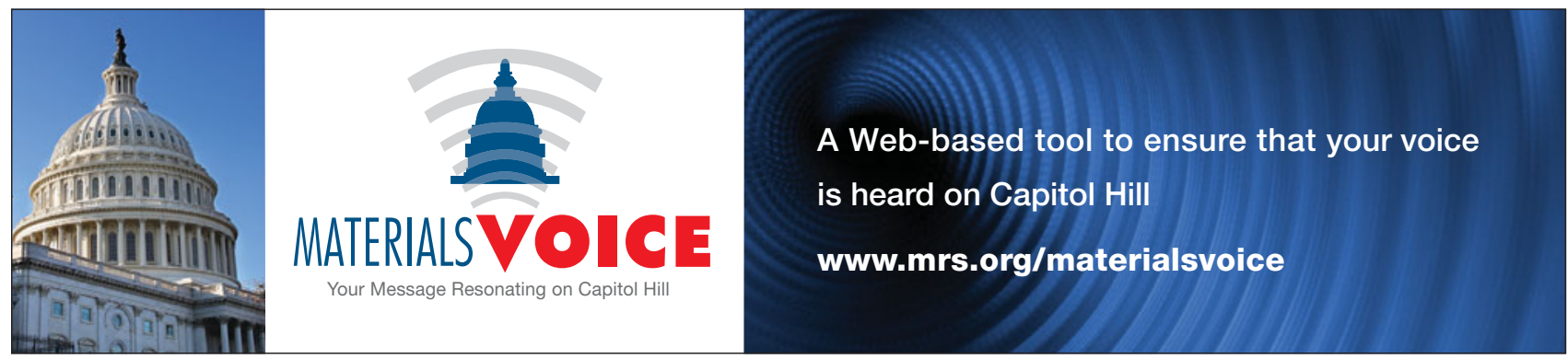